\title{
CONCENTRATION OF MIGRATION BY MARITAL STATUS: A TOPICAL STUDY IN WEST BENGAL
}

Uday Das ${ }^{{ }^{*}} \bowtie(\mathrm{D})$, Jadab Munda 2 凶(iD), Rahul Mondal ${ }^{3}$

${ }^{* 1} \mathrm{PhD}$ Research Scholar (UGC Junior Research Fellow), Visva-Bharati, Shantiniketan, India

${ }^{2}$ MPhil Scholar (UGC Junior Research Fellow), International Institute for Population Sciences, Mumbai, India

${ }^{3}$ MA/MSC in Population Studies, International Institute for Population Sciences, Mumbai, India

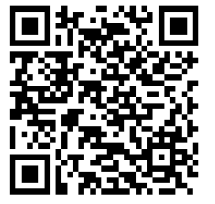

DOI: https://doi.org/10.29121/granthaalayah.v9.i1.2021.2891

Article Type: Research Article

Article Citation: Uday Das, Jadab Munda, and Rahul Mondal. (2021). CONCENTRATION OF MIGRATION BY MARITAL STATUS: A TOPICAL STUDY IN WEST BENGAL.

International Journal of Research GRANTHAALAYAH, 9(1), 37-48. https://doi.org/10.29121/granthaa layah.v9.11.2021.2891

Received Date: 22 December 2020

Accepted Date: 24 January 2021

Keywords:

Marital Status

Marriage

Migration

India

\section{ABSTRACT}

Migration-study holds some classic question as like who migrate, why migrate and where to migrate. Migration researcher delegates their attention to summarizing the nature of migrants ('who') based on sex, age, and the caste to guide who migrate. Demographers do not pay much attention to the marital status of the migrants. The marital status of the migrants ('who') is a significant controlling factor on human mobility. Marriage is a monumental institution in population dynamics, which proximately determines the socio-economic behaviour of the individual. Marital status sometime works as an obstacle and an opportunity for migrants. This study attempts to discover pattern and concentration of migration by marital status and sex to the district of West Bengal from different states and Union Territories (UTs) of India, enumerated by Place of Last Residence (POLR) in 2011, through cluster analysis. The present study finds ever married female migration is much higher than ever married male and never married migration is male-dominated. Marriage is the main reason for female migration, and job opportunities consist of male migration.

\section{INTRODUCTION}

Economically migration is a utility maximization approach for the labour and process of spatial equilibrium between supply and demand of human resource. Migration occurs permanently or semi-permanently by the change of residence (lee 1966). Different push and pull factors and intervening obstacles and opportunities are determined the stream of migration. Thousands of migration-related studies have discussed stream of migration relating to education, age, labour force, sex and caste and so on but only five or six previous studies have explained the stream of migration based on the marital status of the migrants in India by place of last residence. Singh (1986) conducted a study on marital status and migration based on the 1971 census. In his study was cover Bihar, West Bengal and Kerala. Another study about marital status and migration conducted by Premi (1980) he finds more than two-third married migrants are female. Premi also remarked that when distance increases, the migrant's sex ratio is keen to decreases. Ever-married females are more concerning to migrate than ever-married males. In Kerala, married persons migrated with their whole family, but in West Bengal and Bihar, they migrate alone (Singh 1985). Parida \& Madheswaran (2011) comprises marital status in their empirical study based on NSS data, and they declare marital

(C) 2021 The Author(s). This is an open access article distributed under the terms of the Creative Commons Attribution License, which permits unrestricted use, distribution, and reproduction in any medium, provided the original author and source are credited. 
status is an important influence factor in the subject of migration. Kaur's (2012) in his paper on cross-border marriage migration has described females migrate high sex ratio region to skewed sex ratio region and UP performs as a destination place. Trafficking and marriage play a crucial role in female migration in the Indo-Bangladesh border.

Marriage is a significant transitional milestone for human life, and in Indian society, it has extreme socio-cultural importance. So, Marital status sometime works as an obstacle and an opportunity for migrants. In West Bengal, the stream of migration or shifting of population influenced by marital status of the migrants. Less information is available on marital status and migration, so, this paper is a fresh attempt to fill this gap. This paper tries to glorify marital status as a determinant factor during migration, and also focused on sex-wise ever married and never married spatial migration phenomena in West Bengal by using cluster analysis.

\section{DATA AND METHODOLOGY}

Marriage is an important institution in population dynamics, which proximately determines the socio-economic behaviour of the individual. It is a transitional milestone in human life, which is a duality of intervening opportunity and obstacle. For a woman it is an opportunity to change her social position which lessen obligations and maximises responsibility, while in the patriarchal system in India, increased share of workload and liabilities of the household shifts to the man with marriage. Consequently, it exerts a direct influence on the mobility of individuals. This study attempts to discover pattern and concentration of migration by marital status and sex to the districts of West Bengal from different states and Union Territories (UTs) of India, enumerated by Place of Last Residence (POLR) in 2011, through cluster analysis. For this study we have extracted data on migrants by place of last residence, age, sex, marital status for duration of residence 0-9 years for districts of West Bengal, from Census of India, 2011. The pattern of migration by marital status is studied under four streams of migration i.e., Rural-Rural, Rural-Urban, Urban-Rural, Urban-Urban. We have considered migrants of all ages and categorically defined their marital status into two types: (i) Ever Married, and (ii) Never Married, further decomposed by their sexes. Ever-married migrants including currently married, widowed, divorced and separated, while the never-married migrants include the unmarried migrants in 2011. We have also taken into account the Total migrants in each stream for comparing and identifying the responsiveness of marital status to migration. This develops twelve categories, including (i) Total, (ii) Ever Married and (iii) Never Married, in each of the four streams i.e., (a) R-R, (b) R-U, (c) U-R, (d) U-U, and the evermarried and never-married migrants decomposed into male and female.

For the analysis of the intensity of the responsiveness of marital status to migration, we have calculated rate of migrants by their marital status and sex per thousand total migrants enumerated by POLR in different districts of West Bengal in 2011, migrated from states and UTs of India in one of the four streams of migration. The rate is obtained as:

Rate of Migration by Marital Status (R-R/R-U/U-R/U-U) in $2011=$

Number of migrants by sex and marital status in a district

Total migrants in West Bengal

\section{Cluster Analysis}

The clustering is performed with the rate of migration by marital status and sex to the districts of West Bengal in 2011, in Geoda software, through K-means algorithm to discover spatial pattern and concentration of their distribution. The K-means algorithm gives separation of clusters by grouping $n$ observations into $k$ clusters such that within-cluster similarity is maximum and between-cluster similarity is minimum. It considers squared Euclidean distance as the measure of dissimilarity:

$$
d^{2}{ }_{i j}=\sum_{v=1}^{p}\left(x_{i v}-x_{j v}\right)^{2}=\left\|x_{i}-x_{j}\right\|^{2}
$$

Where, $\mathrm{p}$ is number of variables/dimensions (Anselin,2018). 
The algorithm minimises the sum of (one half) of all squared distance by minimising the sum of squared deviation from mean, and the within sum of square is obtained as:

$$
\min (W)=\min \sum_{h=1}^{k} n_{h} \sum_{i \in h}\left(x_{i}-\bar{x}_{h}\right)^{2}
$$

Where, $\bar{x}_{h}$ is the mean of $x$ for cluster $h$ and the index is repeated $n_{h}$ times (Anselin, 2018).

We have implemented K-means++ approach which uses the iterative relocation heuristic, where probability of selecting new seed changes with distance function. If the initial seed, $C_{1}$, is chosen by uniform random selection, the probability of selecting the remaining observations are estimated as (Anselin, 2018):

$$
p_{j \neq c_{1}}=\frac{d^{2}{ }_{j c_{1}}}{\sum_{j \neq c_{1}} d^{2}{ }_{j c_{1}}}
$$

The clustering is performed with the rate of migrants by marital status and sex per thousand total migrants in each streams of migration, enumerated by POLR in the districts of West Bengal in 2011, considering the number of clusters $(k)$ as 5 , initialisation re-runs as 1000 , maximum iterations equal to 1000 and minimum bound of 5 percent. The sum of aggregates of rates in each cluster in respective categories are also presented.

\section{RESULT AND DISCUSSION}

\subsection{RURAL-RURAL STREAM OF MIGRATION}

\subsubsection{TOTAL}

Five clusters have been formed with the districts of West Bengal, based on the rate of migrants by sex per 1000 total migrants (persons), by Place of Last Residence (POLR) in rural-to-rural stream of migration in 2011. The clusters have the ratio of between to total sum of squares 0.896097. Paschim Medinipur and Purba Medinipur form cluster 5 with the aggregate rate of 14.77 in male and 144.59 in females. This cluster have the lowest within cluster sum of squares among all the clusters in this category with the value of 0.0513792, making it distinct from the others, but greater similarity within the cluster. Cluster 4 is formed by Murshidabad, Barddhaman and South 24 Parganas, with the highest aggregate rates of 41.45 in male and 225.02 in female. While three districts of Nadia, North 24 Parganas and Hugli constitutes cluster 3 with a comparatively lower sum of aggregates of rates, which are 36.45 in male and 167.67 in female. Cluster 2 consists of four districts i.e., Jalpaiguri, Malda, Birbhum and Bankura, where the rate of rural-to-rural migration is 29.30 males and 166.83 females per thousand total migrants (persons). Cluster 1 is constituted by four North Bengal districts i.e., Darjeeling, Cooch Bihar, Uttar Dinajpur and Dakshin Dinajpur, and other three districts Purulia, Haora and Kolkata, having the highest within cluster sum of squares 2.60125, reflecting the diverse nature of migration to the districts within this cluster. The cluster have aggregate rates of 23.69 in male and 150.22 in female, showing the lowest average among the clusters in this category. The rate of female migrants outnumbers the rate of male migrants in each cluster and in this category of total migrants by sex in rural-to-rural stream as a whole, where the magnitude of the rate is 145.68 for male and 854.32 for female.

\subsubsection{EVER MARRIED}

Clustering performed with the rate of ever married migrants by sex per thousand total migrants (persons) by POLR in the districts of West Bengal in rural-to-rural stream in 2011, considering $k$ as 5 we got the ratio of between to total sum of squares, 0.872691. Like in the category of total migrants irrespective of their marital status, Paschim Medinipur and Purba Medinipur form cluster 5 in this category, with rates of 7.39 for male and 137.97 for females. Cluster 4 is formed by Koch Bihar, Uttar Dinajpur and Purulia with low rates of 5.74 for male and 91.29 for female. While four districts i.e., Darjeeling, Dakshin Dinajpur, Haora and Kolkata forming cluster 3 have the lowest aggregate 
of rates in this category which are 5.64 for male and 48.35 for female. Cluster 2 constituted by Murshidabad, Barddhaman, North 24 Parganas and South 24 Parganas have the highest sum of aggregates of rates, which have the value of 21.51 for male and 256.72 for females. In ever married category North 24 Parganas joined the three districts of Murshidabad, Barddhaman and South 24 Parganas who formed the cluster with highest rate in the preceding category of total migrants. Cluster 1 is formed by six districts, consisting of Jalpaiguri, Malda, Birbhum, Bankura, Nadia and Hugli, which follows the cluster 2 in terms of magnitude of aggregates of rates. Rate of male in this cluster is 20.14 and 243.89 females per thousand total migrants (persons). The rates of female migrants dominate the rate of male counterpart in each cluster and for the ever-married category as a whole. The rate of female migrants in this category is 778.21 and 61.41 for male makes the overall rate in this category as 838.63 , which reflects the fact that the rural-to-rural migration in the districts of West Bengal by POLR in 2011 is dominated by migrants in ever married status, with a large magnitude of difference.

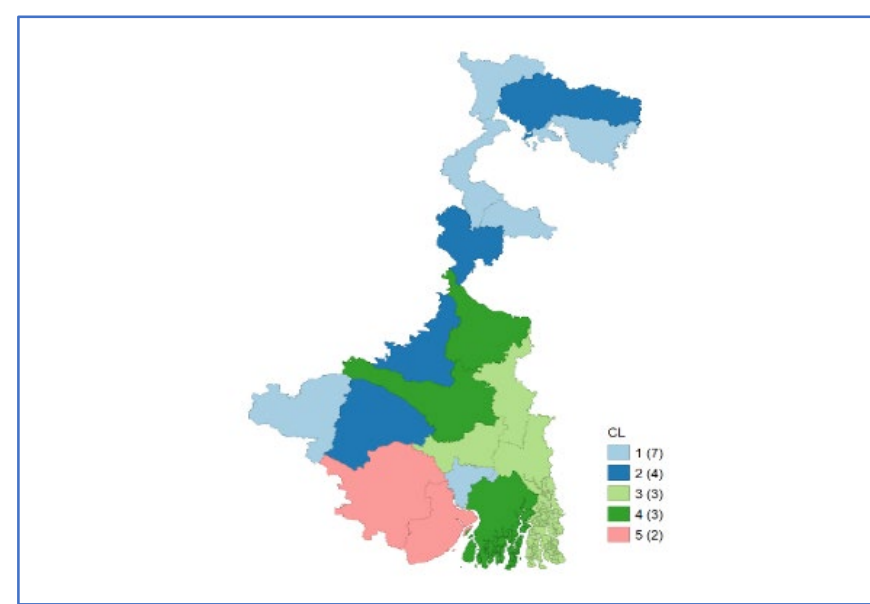

Figure 1.i: Clusters of Total Rural to Rural Migration

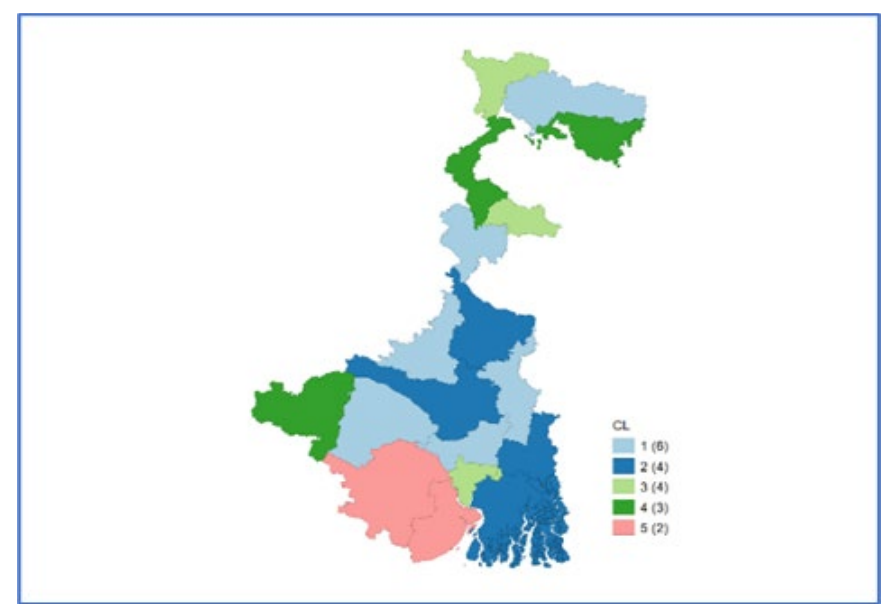

Figure 1.ii: Clusters of Rural to Rural Ever Married Migration

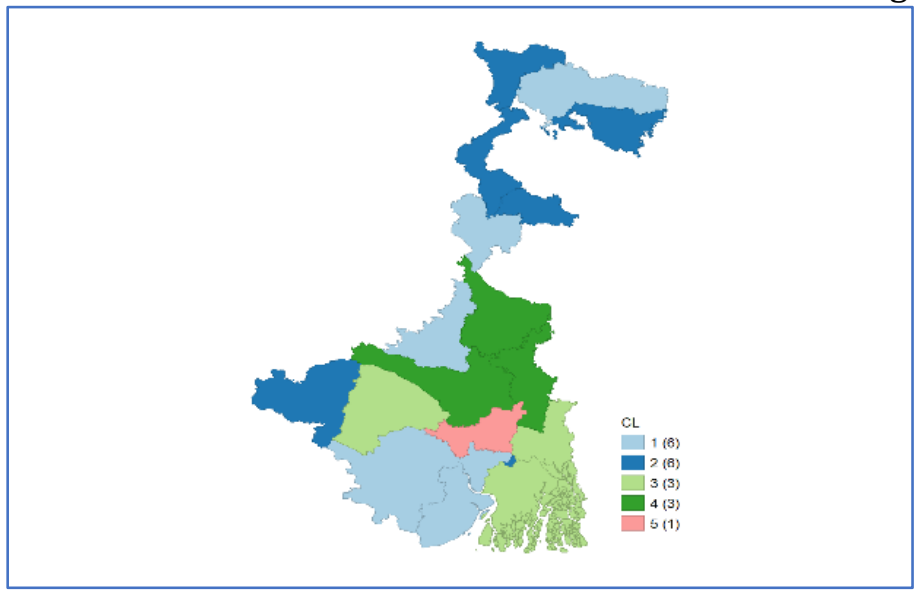

Figure 1.iii: Clusters of Rural to Rural Never Married Migration

Figure1: Cluster wise Rural to Rural Migration Phenomena in West Bengal

\subsubsection{NEVER MARRIED}

Clustering of the district of West Bengal on the basis of rate of never married migrants by sex per thousand total migrants (persons) by POLR in the rural-to-rural stream of migration in 2011, considering $k$ as 5 , have the ratio of between to total sum of squares, 0.972244 . Hugli alone forms cluster 5 with rates of 8.11 for male and 7.46 for their female counterpart. Cluster 4 is formed by Murshidabad, Barddhaman and Nadia, having highest aggregate of rates in this category with 28.47 males and 25.81 females per thousand total migrants (persons). The district Murshidabad remained in the cluster of highest rates in all three categories in the rural-to-rural stream of migration. Bankura, North 24 Parganas and South 24 Parganas constitutes cluster 3 with rates of 17.50 for male and 15.54 for female. 
North 24 Parganas and South 24 Parganas shifted from cluster with highest rate in the ever-married category to a cluster of comparatively lower rates in the never married category. Cluster 2 consists of North Bengal district of Darjeeling, Koch Bihar, Uttar Dinajpur and Dakshin Dinajpur, and the district of Purulia and Kolkata, with lowest average aggregates of rates. In this cluster the rate of male is 9.14 for male and 7.64 for their female counterpart. Jalpaiguri, Malda, Birbhum, Haora, Paschim Medinipur and Purba Medinipur forms cluster 1 with rates of 22.04 for male and 19.65 for their female counterparts. Purba Medinipur and Paschim Medinipur formed a cluster with a considerably dominant rates in Total and Never Married category, whereas in this category it joined cluster with comparatively lower aggregate rates. Unlike other two categories in this category of never-married migrants' rate of male outnumbers the female, but the difference in the values is comparatively less. The overall rate of male is 85.26 and 76.11 for female, which makes the rate of 161.37 for persons in the never married category. It reflects the fact that the never married migrants have a nominal share in the rural-to-rural stream of migration.

\subsection{RURAL-URBAN STREAM}

\subsubsection{TOTAL}

Clusters formed with the rate of migrants by sex per 1000 total migrants from states and UTs of India to districts of West Bengal in rural to urban stream, enumerated on the basis of place of last residence in 2011. Taking $k$ as 5, we have the ratio of between to total sum of squares, 0.96627 . North 24 Parganas singularly forms cluster 5 with the rate of 75.91 for male and 104.07 for female. This district has the larger rate of migrants than the state capital, Kolkata, having one of the megalopolises of India. The average of aggregate rate of migrants is highest for North 24 Parganas in this category. Kolkata, along with the district Hugli constitutes cluster 4 with rate of migrants 66.90 for male and 81.63 for female. Cluster 3 consists of Barddhaman, Haora and South 24 Parganas, having highest sum of aggregate rates of migrants in this category, i.e., 99.58 for male and 204.90 for female, and follows cluster 5 in terms of average. Jalpaiguri, Murshidabad, Nadia and Purba Medinipur form cluster 2, having rate of 65.55 males and 135.56 females per thousand total migrants (persons) by POLR in rural to urban stream of migration in 2011. Cluster 1 is formed by Largest number of districts and having lowest average of aggregate rates in this category. Nine districts including Darjeeling, Koch Bihar, Uttar Dinajpur, Dakshin Dinajpur, Malda, Birbhum, Bankura, Purulia and Paschim Medinipur form this cluster with rates of 61.65 for male and 104.24 for female. Paschim Medinipur and Purba Medinipur shows contrasting response to migration in rural to urban stream than in rural-to-rural stream where they formed clusters with dominant rates. The rates of male in each cluster are outnumbered by their female counterpart, as well as for the state as a whole where the rates for male is 369.59 and 630.41 for female. But the differences in the rates of male and female is considerably lower than in the rural-to-rural stream of migration in 2011.

\subsubsection{EVER MARRIED}

Five clusters formed with rate ever married migrants by sex per thousand total migrants (persons) by POLR in rural to urban stream in 2011, considering $k$ as 5 , have the ratio of between to total sum of squares, 0.966078 . Like in the preceding category, North 24 Parganas singularly forms cluster 5, with the rate 43.43 for male and 83.70, which is much lower than the rates if marital status is not taken into account. However, the rates of ever-married migrants surpass that of Kolkata in this rural to urban stream of migration. Kolkata and Hugli constitute cluster 4 having rates of 34.89 males and 61.59 females per thousand migrants (persons) by POLR from the states and UT is of India following the characteristics of this category. Cluster 3 is formed with three districts including Barddhaman, Haora and South 24 Parganas, with the rate 56.05 for male and 173.87 for female, which is the largest sum of aggregate rate in this category. While another three districts, which are Jalpaiguri, Murshidabad and Nadia forms cluster with rates much lower than later, i.e., 27.79 for male and 94.50 for female. Cluster 1 is constituted by largest number of districts and having lowest average of aggregates, that reflects low responsiveness of these districts to migration following this category. Ten districts including five North Bengal districts, i.e., Darjeeling, Koch Bihar, Uttar Dinajpur, Dakshin Dinajpur and Maldah, and five South Bengal districts including Birbhum, Purulia, Bankura, Paschim Medinipur and Purba Medinipur constitutes cluster 1 with sum of aggregates rates of 39.31 for male and 105.34 for female. Purba Medinipur joins this less responsive cluster whenever married status is considered in this 
rural to urban stream. In this category also male rate is lower than the female rate in each cluster and for the category as a whole. The rates of male over all the clusters are 201.48 for male and 519.00 for female, which makes over all rates of ever married migrants in the rural to urban stream, 720.48 per thousand total migrants (persons) by POLR in 2011. The rates of male in this category showed a considerable increase with reference to the ever-married category in the rural-to-rural stream.

\subsubsection{NEVER MARRIED}

Clustering of the districts of West Bengal on the basis of rate of never married migrants by sex from states and UTs of India in rural to urban stream in 2011, enumerated by place of last residence, with $k$ as 5 , have the ratio of between to total sum of squares, 0.980115 . North 24 Parganas, in this category also, form cluster 5 with highest average of aggregate rate, i.e., 32.48 for male and 20.37 for female. Cluster 4 consists of Kolkata and South 24 Parganas having the rates of 28.19 male 17.49 female migrants per thousand total migrants (persons) following this category. Barddhaman, Hugli and Haora form cluster 3 having rates of 47.34 for male and 33.57 for female migrants, which is the largest sum of aggregate rate in this category. Six districts including Darjeeling, Jalpaiguri, Uttar Dinajpur, Murshidabad, Nadia and Purba Medinipur constitutes cluster 2 with the rate of male migrants, 43.94 and 29.46 for that of female. Darjeeling, which showed more or less inert behaviour, belonging to the less responsive cluster 1 in other categories in this stream, moved to cluster 2 with higher rates in this category. Cluster 1 consists of seven districts including Northern districts of Koch Bihar,

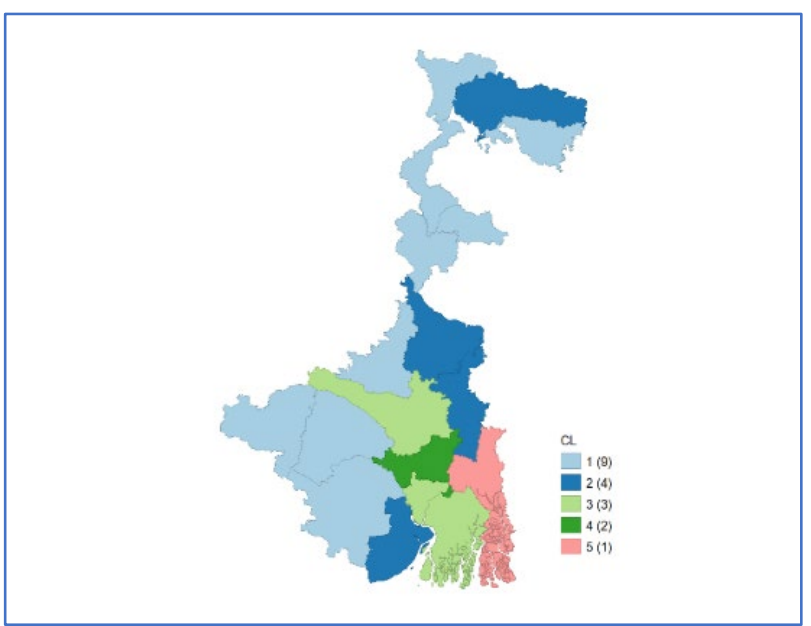

Figure 2.i: Clusters of Total Rural to Urban Migration

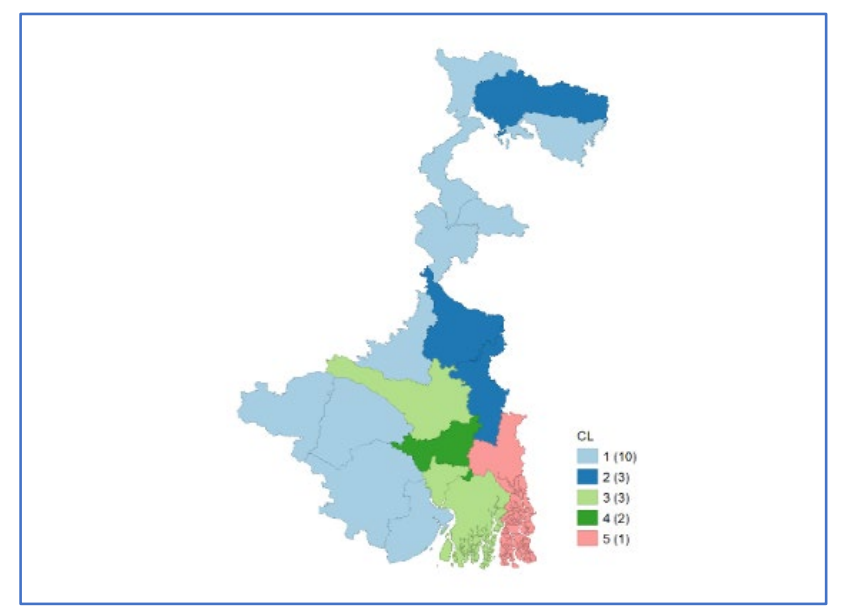

Figure 2.ii: Clusters of Rural to Urban Ever Married Migration

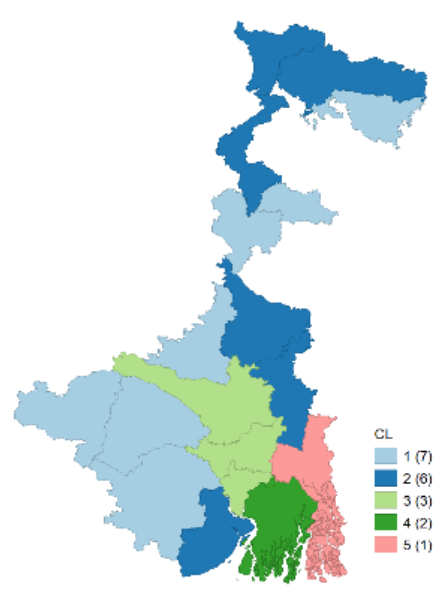

Figure 2.iii: Clusters of Rural to Urban Never Married Migration

Figure 2: Cluster wise Rural to Urban Migration Phenomena in West Bengal 
Dakshin Dinajpur and Malda, and South Bengal districts of Birbhum, Purulia, Bankura and Paschim Medinipur, with lowest rates in this category i.e., 16.16 for male and 10.51 for female, making very nominal average for the districts in this cluster. The rates of male migrants dominate that of female for the clusters individually and for the category as a whole, with the rates 168.11 for male and 111.41 for female. The overall rate for this category of never married migrants i.e., 279.52 is much lower than that of its ever-married counterpart. This stream of migration is responsive to ever-married migrants (by POLR), but the intensity of the responsiveness is lower than in the ruralto-rural stream of migration in 2011.

\subsection{URBAN-RURAL STREAM}

\subsubsection{TOTAL}

Five clusters formed with the rate of migrants by sex per thousand total migrants (persons) from states and UTs of India to the districts of West Bengal by place of last residence in the urban to rural stream of migration in 2011 have the ratio of between to total sum of squares, 0.960385 .

Barddhaman and Nadia constitutes cluster 5 with largest average aggregate rate in this category. The sum of aggregate rates for male is 98.27 for male and 143.93 for their female counterpart. Cluster 4 consists of Jalpaiguri, Murshidabad and Paschim Medinipur with a comparatively lower sum of aggregate rates i.e., 67.73 for male and 104.87 for female. Four districts of West Bengal including Bankura, Hugli, North 24 Parganas and South 24 Parganas forms cluster 3 having the largest sum of aggregate rates among the clusters following this category, and follows cluster 5 in terms of average of aggregate rates. The rates of migrants in this cluster are 141.21 for male and 216.60 for female. Cluster 2 constituted by five districts including North Bengal districts of Uttar Dinajpur, Dakshin Dinajpur and Malda, and Southern districts of Purulia and Kolkata, with lowest aggregate rates i.e., 20.24 males and 45.37 females per thousand migrants (persons) to these districts, enumerated by POLR in urban to rural stream in 2011. While Darjeeling, Koch Bihar, Birbhum, Haora and Purba Medinipur forms cluster 1 with rates of migrants 59.54 for male and 102. 24 for female. The rates of female in this category also are larger than that of their male counterpart in each cluster which makes overall rate of 386.99 for male and 613.01 for female. The striking fact is that the gap in the percentages of the sexes is lower than the preceding streams of migration in 2011.

\subsubsection{EVER MARRIED}

Clustering algorithm performed with the rate of ever married migrants by sex per thousand total migrants (persons) in urban to rural stream, enumerated by place of last residence in districts of West Bengal in 2011. Considering $k$ as 5 we have the ratio of between to total sum of squares as 0.937791 .

South 24 Parganas singularly forms cluster 5 with rates of 13.08 for male and 38.95 for female migrants, while the district was in cluster 3 when ever-married status was not taken into account exclusively. North 24 Parganas and Barddhaman formed cluster 4 with aggregate rate of 17.36 for male and 74.36 for female. Barddhaman was constituent of cluster 5 with dominant rates in the category of total migrants in this stream, moved to cluster 4 in this ever-married category. Four districts including northern districts of Darjeeling and Jalpaiguri, and southern districts of .

Haora and Purba Medinipur constitutes cluster 3 with rates of 12.52 males and 49.73 females per thousand total migrants (persons) by POLR following the characteristics of this category. Cluster 2 is formed by Koch Bihar, Uttar Dinajpur, Dakshin Dinajpur, Maldah, Purulia and Kolkata with lowest aggregate rates among all the clusters in this category i.e., 7.58 for male and 43.93 for female. While Six South Bengal districts surrounding Barddhaman, which are Birbhum, Murshidabad, Nadia, Hugli, Purba Medinipur and Bankura form cluster 1 with largest sum of aggregates in this category, i.e., 24.59 for male and 129.46 for female. The rates in each cluster shows female domination as evident in the overall rates of 75.14 for male and 336.42 for female, that makes 411.56 for migrant Persons in ever-married status. The overall rates for ever-married persons showed a striking decline when the place of origin reversed to urban. 


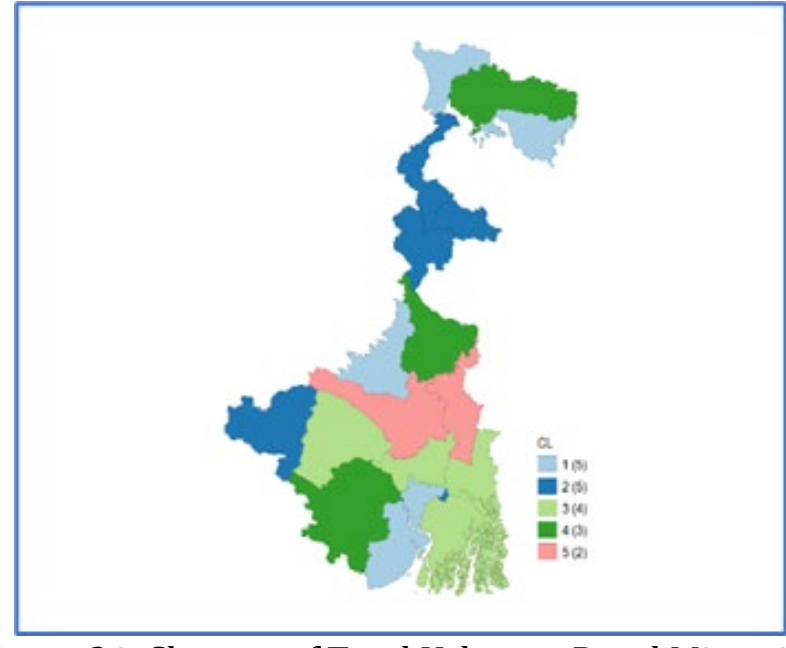

Figure 3.i: Clusters of Total Urban to Rural Migration

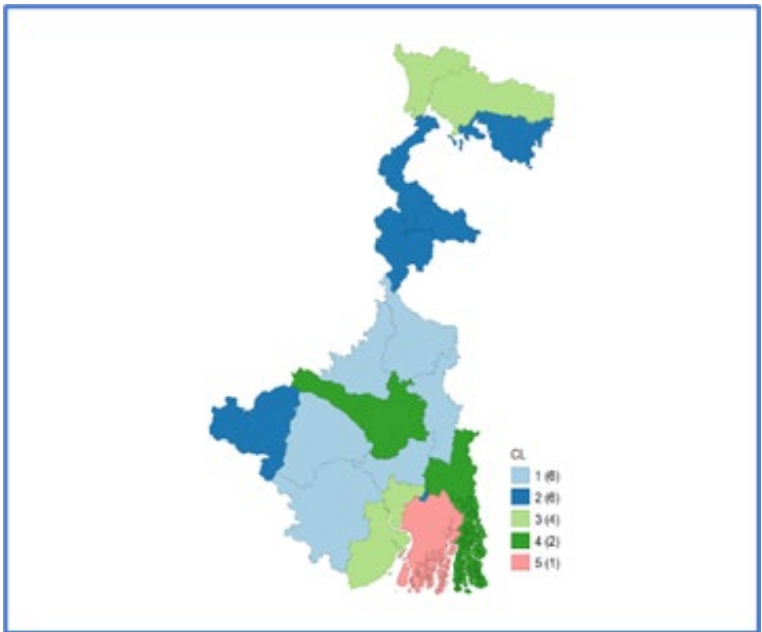

Figure 3.ii: Clusters of Urban to Rural Ever Married Migration

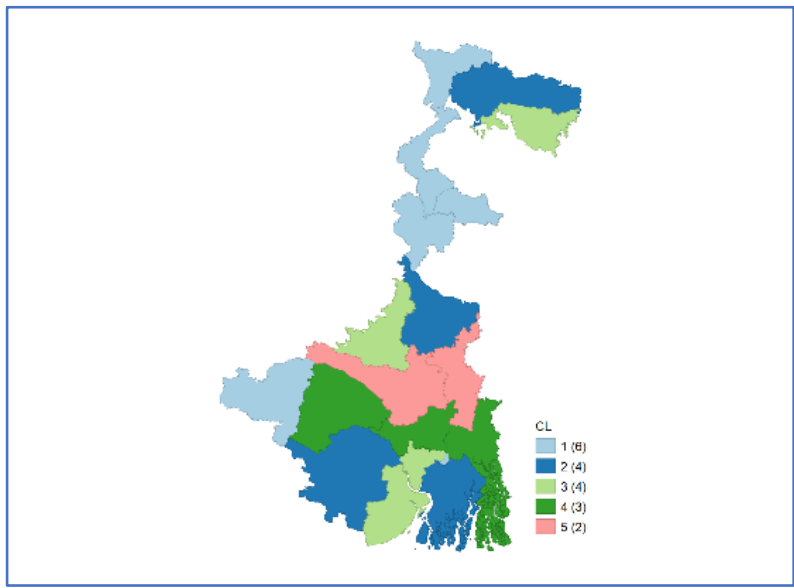

Figure 3.iii: Clusters of Urban to Rural Never Married Migration

Figure3: Cluster wise Urban to Rural Migration Phenomena in West Bengal

\subsubsection{NEVER MARRIED}

Clustering of the districts of West Bengal on the basis of rates of never married migrants per 1000 total migrants (persons) by POLR from states and UTs of India in urban to rural stream in 2011, taking $k$ as 5, we have the ratio of between to total sum of squares, 0.985632 , which is reflective of the very high degree of within similarity and distinctiveness of the clusters.

Like in category of total migrants in this stream, Baddhaman and Nadia forms cluster 5 with most dominant rates in never married status. This high magnitude of this cluster made these two districts form the dominant cluster in the total migrants' category. Cluster 4 consists of Bankura, Hugli and North 24 Parganas with rates of 89.76 for male and 80.15 for female, which is the largest sum of aggregate rates in never married status in U-R stream. Four districts including Koch Bihar, Birbhum, Haora and Purba Medinipur form cluster 3 with 39.50 male and 34.69 female per thousand total migrants (persons) of the specified characteristics in this category. While Jalpaiguri, Murshidabad, South 24 Parganas and Paschim Medinipur constitutes cluster 2 with lager rates than later cluster, i.e., 76.50 for male and 68.10 for female. South 24 Parganas which singularly formed dominant cluster by ever-married status moved to cluster 2 here, and impact of this can be noted in the total migrants' category in this stream where it joined cluster with comparatively lower average rate. Cluster 1 is formed by Northern districts of Darjeeling, Uttar Dinajpur, Dakshin Dinajpur, Malda, Purulia and Kolkata, having lowest aggregate rate of 19.83 for male and 15.68 for female. The rates of male are higher than that of its female counterpart in each cluster as reflected in the overall rates i.e., 311.85 for male and 276.59 for female. The overall rates of migrants (persons) in never married status, 
Uday Das, Jadab Munda, and Rahul Mondal

588.44, dominates over the rate of their ever-married counterpart in this U-R stream. With enumeration of the place of last residence as Rural and origin as Urban the category with higher rates shifted to the never-married status.

\subsection{URBAN-URBAN STREAM}

\subsubsection{TOTAL}

Clustering of the districts of West Bengal with respect to the rates of migrants decomposed into sexes per thousand total migrants (persons) by place of last residence to these districts form states and UTs of India in urbanto-urban stream of migration in 2011 , considering $k$ as 5 , we have the ratio of between to total sum of squares, 0.995646 , giving finest clusters with very high within similarity and between dissimilarity.

North 24 Parganas form cluster 5 with highest rate among all clusters in this category i.e., 162.25 for male and 215.94 for female migrants. North 24 Parganas forms dominant cluster when the place of destination is urban. Bardhhaman and Hugli constitute cluster 4 with comparative lower sum of aggregate rates, i.e., 69.66 for male and 111.32 for female. While cluster 3 is formed by Howrah and South 24 Parganas with rates, 70.12 for male, higher than that in the later cluster, and 97.29 for female, which is lower than in cluster 4. Jalpaiguri, Nadia and Kolkata form cluster 2 with rates 60.55 males and 82.94 females per thousand total migrants (persons) in this stream. The district Kolkata with one of the Mega cities of India joined this cluster with comparatively lower average of aggregate rates. Eleven districts of India, including all the districts of North Bengal except Jalpaiguri, South Bengal districts of Murshidabad, Birbhum, Purulia, Bankura, Paschim Medinipur and Purba Medinipur, forming cluster 1 with responsiveness almost inert to urban-to-urban stream of migration. This cluster is having rates of 50.92 for male and 79.01 for female migrants. The clustering shows that urban to urban migration in West Bengal in concentrated largely to the south-eastern districts. The rate of female migrants dominates over that of their male counterpart in each cluster and consequently in the overall rates for the sexes, i.e., 413.50 for male and 586.50 for female. But the gender difference in the rate of migration in the U-U stream is lowest among all the specified stream in 2011.

\subsubsection{EVER MARRIED}

Five clusters formed with the districts of West Bengal on the basis of rate of ever-married migrants by sex per 1000 total migrants (persons) by POLR in U-U stream in 2011, have the ratio of total to between sum of squares, 0.995454 .

Kolkata singularly forms cluster 5 with rates, 13.25 for male and 19.63 for female, comparatively much lower than cluster 4 formed by North 24 Parganas with rates 78.58 for male and 147.24 for female. Bardhhaman, Hugli, Haora and South 24 Parganas constitute cluster 3 having rates of 65.27 male and 54.47 females per 1000 Total Migrants (persons) in this stream. While Cluster 4 consisting of Darjeeling, Jalpaiguri, Murshidabad and Nadia, have rates 22.22 for male and 54.47 for female, considerably lower than in cluster 3 . Nine states including northern districts of Koch Bihar, Uttar Dinajpur, Dakshin Dinajpur and Malda, and southern districts of Birbhum, Purulia, Bankura, Paschim Medinipur and Purba Medinipur forms cluster 1 with rates 14.10 for male and 38.22 for female, reflecting the lowest degree of responsive to migration in this stream. The rate of male outnumbers that of their female counterpart in each cluster and aggregate over the category, i.e., 193.42 for male and 406.63 for female. The overall rates for migrants (persons) in this category is 600.06, showing dominance in the U-U stream.

\subsubsection{NEVER MARRIED}

Clustering algorithm performed with the districts of West Bengal, considering the rates of never married migrants per thousand total migrants (persons) by POLR in the U-U stream in 2011. Taking $k$ as 5, we have the ratio of between to total sum of squares, 0.997522 . 


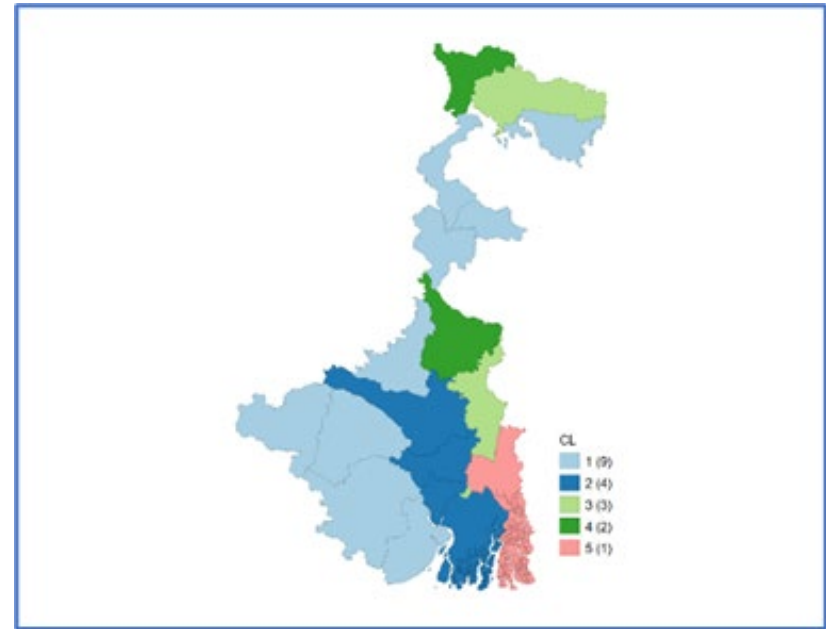

Figure 4.i: Clusters of Total Urban to Urban Migration

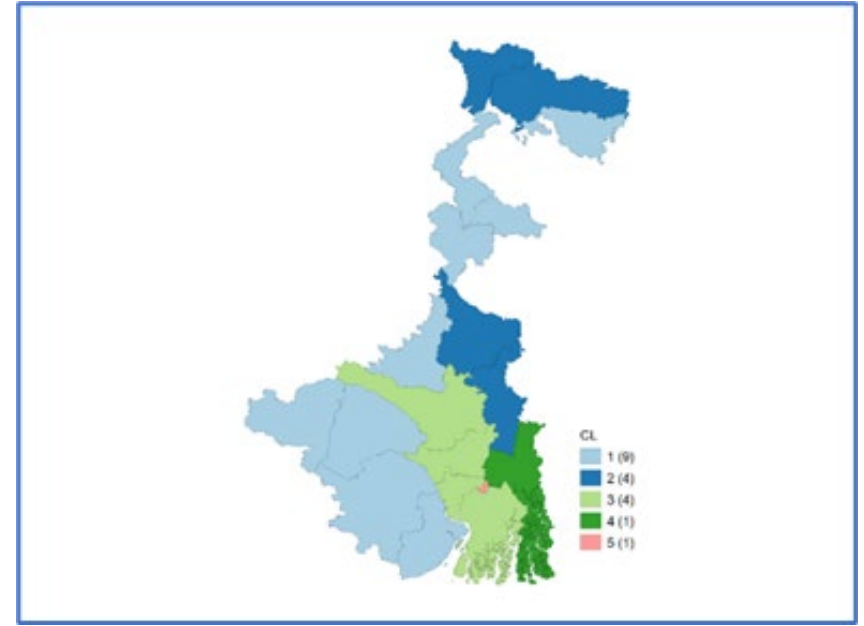

Figure 4.ii: Clusters of Urban to Urban Ever Married Migration

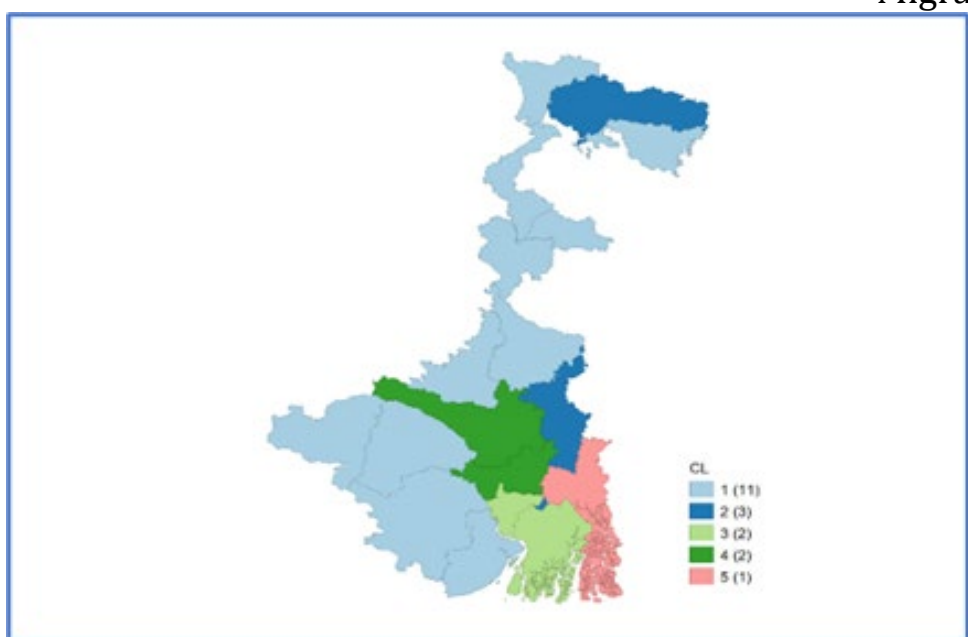

Figure 4.iii: Clusters of Urban to Urban Never Married Migration

Figure 4: Cluster wise Urban to Urban Migration Phenomena in West Bengal

North 24 Parganas singularly form cluster 5 having rates, 83.67 for male and 68.70 for female migrants, showing highest responsiveness to migration in this category, while the gender difference is also highest in this category with male dominance. Darjeeling and Murshidabad constitutes cluster 4 with sum of aggregate rates of 11.21 for male and 9.26 for female. Whereas, cluster 3 consisting of Jalpaiguri, Nadia and Kolkata, have rates, 33.98 for male and 27.67 for female. District Kolkata singularly formed a cluster in the ever-married category, but following the algorithm it joined cluster 3 in this category. Bardhhaman, Hugli, Haora and South 24 Parganas formed cluster 2 with rates of 74.51 for male and 61.55 for female, second largest sum of aggregate rates in this category. Nine districts, including North Bengal districts of Koch Bihar, Uttar Dinajpur, Dakshin Dinajpur and Malda, and South Bengal districts of Birbhum, Purulia, Bankura, Paschim Medinipur and Purba Medinipur constitute cluster 1 with rates of 16.70 males and 12.67 females per 1000 total migrants (persons) by POLR in the U-U stream. This cluster have the lowest average of aggregate rates, reflecting the nature of responsiveness of these districts, almost inert to the $U$ - $U$ migration in 2011, considering never-married status. The rates for male dominate over their female in each cluster, as reflected in the overall rates, 220.08 for male and 179.87 for female, but in contrary to other categories the gender differences in the sex are significantly lower in this category. The overall rate of migrants (persons) with nevermarried status, i.e., 399.94, is lower than it's ever-married counterpart in the U-U stream. Rate of Migrants (persons) by POLR in the districts of West Bengal in 2011, with ever-married status dominates in each of the four streams of migration, except in the U-R stream of migration. 


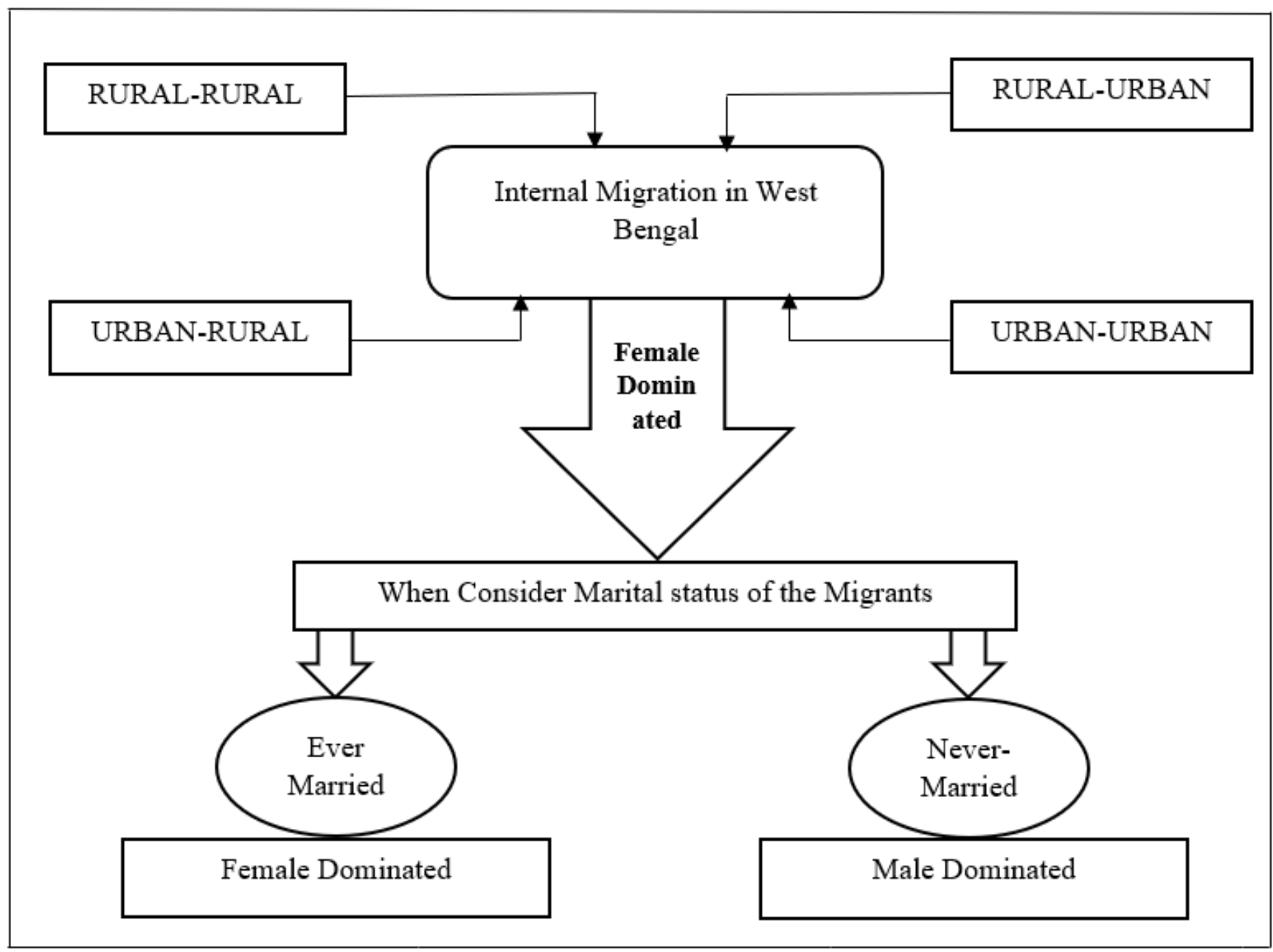

Source: Author

Figure 5: Flow diagram model shows the concept of the study (marital status of the migrants as a significant controlling factor)

\section{SUMMARY AND CONCLUSION}

In West Bengal, rural to rural migration is female-dominated. Every cluster's female migration rate is higher than male migrants, just then when we considered the marital status of the migrants, the figures are noticeable. Every cluster's (rural to rural) ever married female migration rate is much higher than ever married male and never married migration is male-dominated in the stream of rural-to-rural migration. Cluster-2 constituted by Murshidabad, Burdwan, North and South 24 Parganas shows highest ever married female and male migration. In never married rural to rural migration, cluster- 4 formed by Murshidabad, Bardhhaman and Nadia, and shows the highest aggregate of never-married migration, but ever married is female-dominated and never-married is maledominated. In the rural area, female migration is synonymous with marriage migration, and they have to change their residence with their marriage, so ever-married migration is head by the female.

Opening new opportunities and beckons for promoting living standard increased the stream of rural to urban migration. This stream of migration is more economically-induced migration. In West Bengal, less profitable agriculture, job, higher education, marriage, search for a better life proximately determined the stream of rural to urban migration. Cluster-3 consisted of three districts (Bardhhaman, Haora and South 24 Parganas) represents the highest amount of rural to urban migration. Rural to urban stream also female-dominated and every cluster malefemale difference is high except cluster-4. An important finding is ever married rural to urban migration is extremely female-dominated, and cluster-3 shows highest aggregates of the migrants (see figure 2). Interestingly nevermarried rural to urban migration is highly male-dominated and Bardhhaman, Hugli and Haora (cluster-3) having the 
highest amount of never-married rural to urban migrants. Industrially developed district Bardhhaman and their increasing non-agricultural sector pulled factor to attracts migrants.

Urban-rural stream of migration's sum is low and not much significant during internal migration in West Bengal. The aggregate share of female migrants is higher than male migrants. Bankura, Hugli, North and South 24 Parganas (cluster-3) having the highest sum of aggregates. A high land value near the city centre and expansive lifestyles pushed peoples towards the outer fringe. The affection to the native village to enjoy retired life with clean air increasing pulled factors for urban to rural migration. Ever married migration is female dominate and never married migration predominated by the male. Urban to urban migration governed by female but sex-wise aggregates differences are lower than others stream of migration. Industrially backwards and low urbanized districts Koch Bihar, Uttar Dinajpur, Dakshin Dinajpur and Maldah, and southern districts of Birbhum, Purulia, Bankura, Paschim Medinipur and Purba Medinipur shows lower aggregates of urban-to-urban migration by the place of the last residence. Overall, the result is ever married migration predominated by female and never married figure is maledominated. Marriage is the main reason for female migration, and job opportunities pulled male migrants. Never married male migration is higher than ever married male. Intensive information is not available about the effects of marital status during migration decisions. Further study needed to understand the relationships between marital status and decision for movement in the socio-economic perspective.

\section{SOURCES OF FUNDING}

This research received no specific grant from any funding agency in the public, commercial, or not-for-profit sectors.

\section{CONFLICT OF INTEREST}

The author have declared that no competing interests exist.

\section{ACKNOWLEDGMENT}

None.

\section{REFERENCES}

[1] Anselin, L. (2020). Cluster analysis (1): K-means clustering. Retrieved from https://geodacenter.github.io/workbook/7bk_clusters_1a/lab7b.html

[2] Bhagat, R. B. (2011). Internal migration in India: Are the underclass more mobile. Migration, identity and conflict: India migration report.

[3] Bhattacharya, P. (1998). The informal sector and rural-to-urban migration: some Indian evidence. Economic and Political Weekly, 1255-1262.

[4] Census of India 2011

[5] Bowen, L., Ebrahim, S., De Stavola, B., Ness, A., Kinra, S., Bharathi, A. V., ... \& Reddy, K. S. (2011). Dietary intake and rural-urban migration in India: a cross-sectional study. PloS one, 6(6), e14822.

[6] Kaur, R. (2012). Marriage and migration: Citizenship and marital experience in cross-border marriages between Uttar Pradesh, West Bengal and Bangladesh. Economic and Political Weekly, 78-89.

[7] Lee, E. S. (1966). A theory of migration. Demography, 3(1), 47-57.

[8] Parida, J. K., \& Madheswaran, S. (2011). Determinants of migration and remittance in India: Empirical evidence. Institute for Social and Economic Change.

[9] Premi, M. K. (1980). Aspects of female migration in India. Economic and Political Weekly, 714-720.

[10] Singh, J. P. (1985). Marital status and migration in Bihar, West Bengal and Kerala: A comparative analysis. Sociological Bulletin, 34(1-2), 69-87.

[11] Singh, J. P. (1986). Marital status differentials in rural to city migration in India. Genus, 89-106.

[12] Singh, M., \& Shandilya, S. (2012). Internal migration in India. Journal of Business Management \& Social Sciences Research (JBM\&SSR) Volume, 1, 66-69. 